\title{
Ventricular aneurysms, shock, and late follow-up in patients with heart failure
}

Patrick M. McCarthy, MD

See related article on page 374 .
From the Department of Thoracic and Cardiovascular Surgery, Kaufman Center for Heart Failure, Cleveland Clinic Foundation, Cleveland, Ohio

Received for publication March 25, 2003; accepted for publication April 1, 2003.

Address for reprints: Patrick M. McCarthy, MD, Department of Thoracic and Cardiovascular Surgery, 9500 Euclid Ave, F25, Cleveland, OH 44195 (E-mail: mccartp@ccf.org).

J Thorac Cardiovasc Surg 2003;126:323-5

Copyright () 2003 by The American Association for Thoracic Surgery

$0022-5223 / 2003 \$ 30.00+0$

doi:10.1016/S0022-5223(03)00733-5

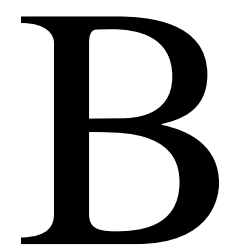

olooki and colleagues ${ }^{1}$ describe their 22 -year experience repairing left ventricular (LV) aneurysms using 3 surgical techniques that were introduced sequentially, with the technique used in group 3 being introduced most recently in 1992. During those 22 years, much has changed in the management of patients with heart failure and in cardiac surgery in general. Routine use of angiotensinconverting enzyme inhibitors and implantable cardioverter-defibrillators started after the initiation of their study. ${ }^{2,3}$ The addition of $\beta$-blockers, spironolactones, and biventricular synchronous pacing was introduced during the 1990s. ${ }^{4-6}$ These interventions for heart failure have had a significant positive effect on the short-term and midterm prognoses for patients. ${ }^{7}$ Therefore, it is no surprise that the midterm survival for their most recent patients is better than that for the patients who underwent surgical intervention at an earlier time (groups 1 and 2).

Was the improvement in survival in group 3 patients as described by Bolooki and colleagues the result of the concept of surgical intervention being inherently better than in the techniques used in group 1 and 2 patients? Although they imply that their results are better, "especially with endoventricular patch technique," with so many other changes evolving during the same time, this is a classic apples and oranges comparison. Unfortunately, no amount of statistical matching would be able to account for the evolution of medical therapy during this period. Furthermore, the patients' pathologies were different, which could make a crucial difference in late outcomes. The group 3 patients were chosen for this procedure because of minimal involvement of the septal wall; therefore these patients had a more localized infarct than those who had a "large dyskinetic septal scar" (group 2). Also, there are no data to compare ventricular volumes or even dimensions to allow more meaningful comparison between the groups. Therefore, with the evolution of medical therapies and different populations, it is not surprising that group 3 patients achieved better 5-year survival, and this cannot be attributed to the surgical technique.

What is surprising is that there was no improvement in perioperative mortality in the more recent group compared with in the groups that began to be treated in 1979 . Surgical procedures also evolved during the past 2 decades, with changes such as more effective techniques of cardioplegia, intraoperative echocardiography, and the availability of new inotropic drugs, such as phosphodiesterase inhibitors. ${ }^{8}$ Most surgeons think that surgical intervention is safer today than it was 22 years ago. Also, the operative mortality in this report is high compared with modern standards. ${ }^{9-11}$ The high mortality probably relates to the inclusion of patients with cardiogenic shock as an indication for surgical intervention. The operative mortality for this group of patients was $46 \%$, and the 3-year survival was $36 \%$. No information was given regarding late functional outcome of the patients with cardiogenic shock. Were those patients still limited by heart failure? There are broadly 2 scenarios in which a patient with an aneurysm would experience shock: an acute infarction in a vessel remote from the aneurysm or progressive disease that has caused remote muscle to fail. If a patient has an aneurysm and then infarction occurs in another vessel, there might be little remaining viable myocardium to support cardiac function. Similarly, if remote areas of muscle are so dysfunctional that the patient experiences shock, there are some problems that conventional cardiac surgery cannot reliably reverse. From these data, it seems that patients with LV 
aneurysms in cardiogenic shock pose one of those problems. Unconventional approaches might be needed in this case, such as mechanical support or transplantation.

Because ventricular dilatation caused by the aneurysm leads to apical displacement of the papillary muscles and functional mitral regurgitation, it is also surprising in this series that mitral valve surgery was rarely used. Mitral regurgitation leads to LV volume overload and might cause late deleterious ventricular remodeling, which is improved with mitral repair. ${ }^{12-15}$ An additional surgical point relates to the size of the remaining LV cavity and the patch. In general, a small patch and smaller LV volumes should lead to a good outcome (group 3 in the series by Bolooki and colleagues ${ }^{1}$ ) unless ventricular volumes are so low that diastolic dysfunction might be created or mitral regurgitation might be increased by distortion of the papillary muscles. ${ }^{15,16}$ We have avoided using a patch reconstruction in more than $95 \%$ of patients, however, by using a doublecerclage technique with ventriculoplasty. ${ }^{11}$ Because replacing a dyskinetic aneurysm with an akinetic patch seems to result in only limited success, we hope that reconstruction without akinetic prosthetic material will lead to better late outcomes. We do not know from this article what the size of the left ventricle was before or after patch repair or whether mitral regurgitation developed after reconstruction.

Bolooki and colleagues, ${ }^{1}$ at the end of their article, make a case for the surgical treatment for ischemic heart failure trial, a randomized surgical trial to help determine the benefits of LV reconstruction, and coronary bypass in this era of improving medical therapies for patients with heart failure. However, should surgeons randomize patients with LV aneurysms, an operation we have been performing successfully since 1958 , because medicines have shown shortterm and midterm improvement in patients with heart failure? I think not. Those trials largely excluded patients with "surgical problems," such as aneurysms or extensive coronary disease with ischemia. Therefore, the results of the medical trials might not apply to a patient population with classic surgical indications. LV aneurysms are mechanical problems that increase wall stress and myocardial oxygen consumption, activate neurohormones, and decrease myocardial efficiency. ${ }^{17,18}$ Mathematic modeling and clinical studies show improvement in remote muscle function after aneurysm repair. ${ }^{19,20}$ Medications might palliate heart failure, but an untreated mechanical problem will lead to poor long-term effectiveness. Because medical therapy has improved does not mean that we need to rethink all our strategies about surgical intervention. Should we randomize patients with aortic stenosis and severe LV dysfunction to medical therapy? No, because there is an underlying mechanical problem that will not be addressed by medication. ${ }^{21} \mathrm{~A}$ much smaller trial to determine the benefit of LV reconstruction for akinetic areas (not aneurysms) might be more useful. Akinetic areas create less of a mechanical problem than true aneurysms, the scar and muscle are heterogeneous, and clinical results are more equivocal. ${ }^{20,22}$ Would coronary artery bypass grafting with reconstruction of an akinetic ventricle be better than coronary artery bypass grafting alone? That would be an important clinical question for a trial. Unlike coronary artery bypass trials, however, this surgical trial is much more difficult because of the complex issues of patient selection, preoperative imaging, intraoperative management (patch versus no patch, management of mitral regurgitation, and extent of LV reconstruction), perioperative care, and follow-up in designated heart failure centers. An international trial to investigate this complex strategy will face many obstacles.

In summary, the reconstruction technique described in group 3 might yield better late results. However, this study does not prove this claim because the patients were significantly different at baseline, and over time, there was a revolution in the treatment of patients with heart failure. This study did demonstrate that LV aneurysm repair is not a very successful strategy for patients with cardiogenic shock. Finally, for patients undergoing surgical intervention for heart failure, late follow-up studies might be of only limited benefit. Like the stock market, past results might not indicate future results. However, with better patient selection, preoperative imaging, perioperative management, and synergistic management of heart failure with our colleagues in cardiology, we should be entering a bull market in the surgical treatment of patients with heart failure.

\section{References}

1. Bolooki H, DeMarchena E, Mallon SM, et al. Factors affecting late survival after surgical remodeling of left ventricular aneurysms. J Thorac Cardiovasc Surg. 2003;126:374-85.

2. Pfeffer MA, Braunwald E, Moye LA, et al. Effect of captopril on mortality and morbidity in patients with left ventricular dysfunction after myocardial infarction: results of the Survival and Ventricular Enlargement Trial. N Engl J Med. 1992;327:669-77.

3. Gabry MD, Brodman R, Johnston D, et al. Automatic implantable cardioverter-defibrillator: patient survival, battery longevity and shock delivery analysis. J Am Coll Cardiol. 1987;9:1349-56.

4. Packer M, Bristow MR, Cohn JN, et al. The effect of carvedilol on morbidity and mortality in patients with chronic heart failure. $N$ Engl J Med. 1996;334:1349-55.

5. Pitt B, Zannad F, Remme WJ, et al. The effect of spironolactone on morbidity and mortality in patients with severe heart failure. Randomized Aldactone Evaluation Study Investigators. N Engl J Med. 1999; 341:709-17.

6. Linde C, Leclercq C, Rex S, et al. Long-term benefits of biventricular pacing in congestive heart failure: results from Multisite Stimulation in Cardiomyopathy (MUSTIC) study. J Am Coll Cardiol. 2002;40:111-8.

7. Levy D, Kenchaiah S, Larson MG, et al. Long-term trends in the incidence and survival with heart failure. N Engl J Med. 2002;347: 1397-402.

8. McCarthy PM. Synergistic approaches in the surgical treatment of heart failure: complex solutions for complex problems. Semin Thorac Cardiovasc Surg. 2002;14:187-19.

9. Athanasuleas CL, Stanley AW Jr, Buckberg GD, Dor V, DiDonato M, Blackstone EH. Surgical anterior ventricular endocardial restoration (SAVER) in the dilated remodeled ventricle after anterior myocardial 
infarction. RESTORE Group: Reconstructive Endoventricular Surgery, returning Torison Original Radius Elliptical shape to the LV. J Am Coll Cardiol. 2001;37:1210-3.

10. Mickleborough LL. Left ventricular reconstruction for ischemic cardiomyopathy. Semin Thorac Cardiovasc Surg. 2002;14:144-9.

11. Caldeira C, McCarthy PM. A simple method of LV reconstruction without patch for ischemic cardiomyopathy. Ann Thorac Surg. 2001; 72:2148-9.

12. Badhwar V, Bolling SF. Mitral valve surgery in the patient with left ventricular dysfunction. Semin Thorac Cardiovasc Surg. 2002;14: 133-6.

13. Bishay ES, McCarthy PM, Cosgrove DM, et al. Mitral valve surgery in patients with severe left ventricular dysfunction. Eur J Cardiothorac Surg. 2000;17:213-21.

14. Hung J, Guerrero JL, Handschumacher MD, et al. Reverse ventricular remodeling reduces ischemic mitral regurgitation: echo-guided device application in the beating heart. Circulation. 2002;106:2594-600.

15. DiDonato M, Sabatier M, Dor V, et al. Effects of the Dor procedure on left ventricular dimension and shape and geometric correlates of mitral regurgitation one year after surgery. J Thorac Cardiovasc Surg. 2001; 121:91-6.

16. Salati M, Paje A, DiBiasi P, Fundaro P, Cialfi A, Santoli C. Severe diastolic dysfunction after endoventriculoplasty. J Thorac Cardiovasc Surg. 1995;109:694-701.

17. Mann DL. Mechanisms and models in heart failure: a combinatorial approach. Circulation. 1999;100:999-1008.

18. Francis GS, Cohn JN. Cardiac failure and the autonomic nervous system. In: Bannister R, Mathias CJ, editors. A textbook of clinical disorders of the autonomic nervous system. 4th ed. Oxford, United Kingdom: Oxford University Press; 1999. p. 477-86.

19. DiDonato M, Sabatier M, Toso A, et al. Regional myocardial performance of nonischemic zones remote from anterior wall left ventricular aneurysm: effects of aneurysmectomy. Eur Heart J. 1995;16:1285-92.

20. Artrip JH, Oz MC, Burkhoff D. Left ventricular volume reduction surgery for heart failure: a physiologic perspective. $J$ Thorac Cardiovasc Surg. 2001;122:775-82.

21. Pereira JJ, Lauer MS, Bashir M, et al. Survival after aortic valve replacement for severe aortic stenosis with low transvalvular gradients and severe left ventricular dysfunction. J Am Coll Cardiol. 2002;39: 1364-5.

22. Dor V, Sabatier M, DiDonato M, Montiglio F, Toso A, Maioli M. Efficacy of endoventricular patch plasty in large postinfarction akinetic scar and severe left ventricular dysfunction: comparison with a series of large dyskinetic scars. J Thorac Cardiovasc Surg. 1998;116:50-9. 